This is the author's version of a work that was accepted for publication in the Journal Renewable Energy. Changes resulting from the publishing process, such as peer review, editing, corrections, structural formatting and other quality control mechanisms may not be reflected in this document. Changes may have been made to this work since it was submitted for publication. A definitive version was subsequently published in the Journal Renewable Energy, Volume 66, June 2014, Pages 228-231.

http://doi.org/10.1016/j.renene.2013.12.007 


\title{
Combined-Cycle Hydropower System - The Potential of Applying Hydrokinetic Turbines in the Tailwaters of Existing Conventional Hydropower Stations
}

Yue Liu ${ }^{*}$, Daniel J. Packey

Department of Mineral and Energy Economics, Curtin University

\begin{abstract}
This paper focuses on discussing the potential and feasibility of increasing the hydropower production by installing hydrokinetic turbines behind existing conventional hydropower facilities to establish "combined-cycle hydropower system (CCHS)". The CCHS will capture additional power from the energy remaining in the water currents exiting dams. There are two modes of CCHS. The hydrokinetic turbine can be located directly behind the turbine of the existing conventional hydropower plant or it can be placed at sites in the vicinity of powerhouse. The challenges and advantages associated with the CCHS are addressed in this paper. Although the technologies of CCHS is still in its research and development phrase, not yet reaches mature and economically feasible; it is believed that it possesses significant potential to produce additional clean hydropower in the large-scale. It may become additional promising way of generating clean energy to mitigate climate change.
\end{abstract}

\section{Highlights}

Two modes of CCHS have been proposed.

The concepts of CCHS have been demonstrated by two projects in the USA.

The CCHS has great potential in producing clean energy.

A scaled up conceptual system-level design, performance, and economic study of the CCHS is needed.

Keywords: combined-cycle hydropower systems, hydrokinetic turbine, conventional hydropower, renewable energy, climate change mitigation

\section{Introduction}

To a visitor on the bank overlooking the rushing tailwaters in the service spillway of a major hydroelectric dam, the raw energy of the rushing water is awe inspiring. To an energy economist, it is a good example of harvestable renewable energy. It is akin to having your spouse spend a good deal of effort to make a beautiful apple pie. Only to have you eat one slice - and a wonderful slice it is - but then tosses the remaining pie into the river. In the real life scenario, the energy contained in the tailwaters of dams is often released to river and wasted.

The energy contained in the water behind the dam has both hydrostatic and hydrokinetic energy. Hydrostatic energy is the potential energy possessed by a body of water because of its position at an elevation or height above a reference or datum [1].

$\mathrm{P}=\eta \rho g Q h$

\footnotetext{
* Corresponding author at: 10 Bordie Hall Drive, Technology Park, Bentley, Western Australia 6102. Tel: + 61 89266 2450. E-mail address: yue.liu2@postgrad.curtin.edu.au
} 
Where, $P$ is the hydrostatic power in watts; $\eta$ is turbine efficiency; $\rho$ is the density of water $\left(\mathrm{kg} / \mathrm{m}^{3}\right) ; Q$ is the flow rate $\left(\mathrm{m}^{3} / \mathrm{s}\right) ; \mathrm{g}$ is the gravitational constant; and $h$ is the height difference between intake and outlet. This is what is used to generate the electricity in a hydroelectric dam.

Hydrokinetic energy refers to energy that is possessed by a body of water because of its motion, such as river or ocean current. It is different from hydrostatic energy; it is the energy resulting from the flow of the water. The hydrokinetic energy resources include tidal energy, river in-stream energy, ocean current energy, ocean wave energy, and constructed waterways current [2].

The power generated by hydrokinetic energy conversion devices will be proportional to the density of the water and to the flow velocity cubed [2].

$\mathrm{P}_{\mathrm{k}}=(1 / 2) \eta \rho A v^{3}$

Where, $P_{k}$ is the hydrokinetic power in watts; $\eta$ is the turbine efficiency; $\rho$ is the density of water $\left(\mathrm{kg} / \mathrm{m}^{3}\right) ; A$ is the area of the rotor blades, $v$ is the fluid velocity $(\mathrm{m} / \mathrm{s})$. The power generated by the devices primarily depends on the speed of the flow current (notice it is calculated with the cube of the velocity).

The technologies developed to extract energy from those hydrokinetic energy resources are called hydrokinetic energy conversion devices. The devices convert the hydrokinetic energy to mechanical power and generate electrical current with generators [2]. Although the concept of hydrokinetic energy has been investigated by researchers since 1979 [3], it is still at early stage of development and being considered as an unusual and promising type of renewable energy for future $[4,5]$.

There are two broad categories for hydrokinetic energy conversion devices: rotating machines and wave energy conversion devices. Rotating machines are normally applied within a stream or current, generating power without impounding or diverting the water flow, which is similar to the wind turbine conceptually. Wave energy conversion devices contain two or more bodies move relative to each other, creating a system of reacting forces with waves [1].

The hydrokinetic energy conversion devices are normally also mentioned as hydrokinetic turbines. The term 'Hydrokinetic Turbine' has been also interchangeable with other names such as, 'Water Current Turbine' (WCT) [6], 'Ultra-low-head Hydro Turbine' [7], 'Free Flow/Stream [8], 'Zero Head Hydro Turbine'[9], or 'In-stream Hydro Turbine' [10].

While there are obvious enthusiasms in the development of marine and tidal hydrokinetic technologies worldwide, there are also growing interests in developing and deploying river in-stream hydrokinetic technologies. River in-stream hydrokinetic turbine (RISHT) systems are considered more environmentally friendly when compared to conventional hydropower and tidal barrages [5]. The conventional hydropower plants require creating artificial water-heads by using of dams for large hydropower projects or penstocks for micro-hydro ones. In contrast, RISHTs are constructed and placed in the river without the requirement of using dams or penstocks. Therefore, it has small alternation to the natural pathway of water stream and the minimal need for civil engineering work compared to conventional large hydropower systems [5].

RISHTs are often mentioned as the technological solution which can provide small-scale renewable hydro power to the remote areas. RISHTs produce small-scale power outputs from sitting hydrokinetic turbines in the free-flowing river. Examples include: Verdant 
Power has conducted a research for Natural Resources Canada [6]; the Electric Power Research Institute (EPRI) conducted a study in river in-stream energy conversion for Alaska river applications [11]; and Zero Emission Resource Organization published an overview of the existing technology of water current turbines with a unit power output of about 0.5-5 kW [12].

In addition to using the RISHTs in the free-flowing rivers to produce small-scale power outputs, the RISHTs also can be placed behind dams of existing conventional hydropower station to generate extra hydropower. This paper focuses on discussing the potential and feasibility of increasing the hydropower production by installing hydrokinetic turbines behind existing conventional hydropower facilities to establish "combined-cycle hydropower systems (CCHS)". The CCHS will generate additional power from capturing the energy remaining in the water current exiting dams. It is believed that there exists significant potential in producing additional renewable power in the large-scale from applying CCHS.

The principle of hydrokinetic power produced from the river flow is similar to that of wind power. They both use the turbine as a media to capture kinetic energy of fluid and convert it to the power. Through comparing to wind turbines, it helps to better understand the scale of energy capacities can be provided by the hydrokinetic turbines. As shown by the equation (2), the power extracted by the hydrokinetic turbine is proportional to the cube of the velocity of flow, the cross-sectional area of turbine, and the density of the water. While the density for wind is approximately $1.223 \mathrm{~kg} / \mathrm{m}^{3}$, the density for water is $1000 \mathrm{~kg} / \mathrm{m}^{3}$ which is about 817 times larger of that of wind's. This indicates that the hydrokinetic turbine is possible to produce much higher energy capacity when compared to a similar sized wind turbine.

Arango (2011) stated that the velocity found at the outlet of the powerhouse draft tubes constitutes a loss in conventional hydroelectric systems and exploiting this kinetic energy would allow for the maximum use of the flow passing through the conventional turbines [13]. Khan et al. (2009) indicated the hydrokinetic turbines could potentially be used in conjunction with an existing hydroelectric facility, where the tailrace of a stream can be utilized for capacity augmentation $[14,15]$. Therefore, there exists the possibility that the RISHTs can be added to the existing conventional hydropower plant to increase its power output.

\section{Challenges}

In order to add hydrokinetic turbines to existing hydropower plants to produce additional power at a large scale, it is important to identify areas in the downstream of existing hydropower facilities where have high flow velocities and sufficient depth to accommodate large diameter hydrokinetic turbines. The proper identification of sites for locating turbines is essential for achieving optimal functionality of turbines and determining the scale of power output and economic viability of a project [11].

In order to identify sites with the greatest potential, it is important to evaluate complicated features of the flow and assess the flow's power density $(P / A)[11,13]$. Arango $(2011)$ has proposed a set of criteria for identifying the power density of downstream regions of the hydropower facilities including: 1) flow velocities above $1 \mathrm{~m} / \mathrm{s}, 2$ ) sufficient depth, 3) ease of access, 4) avoidance of regions prone to large scale dynamic fluctuations, 5) regions with sub-critical flow, 6) sensitivity to environment, and 7) river bed composition [13]. 
River flow velocity is highly site-specific with a three-dimensional profile. The positioning of turbine rotor against such variations will determine the amount of energy that can be effectively extracted by the hydrokinetic turbine [5]. For the purpose of identifying the specific sites and resources potential for the conjunction use of hydrokinetic turbine with existing conventional hydropower facilities, for assessing the level of its power output, it is important to establish the correlation between potential site' flow variation and site bathymetry, select and operate the hydrokinetic turbine accordingly to achieve the optimal energy extraction [14].

As an emerging alternative way of producing renewable energy, there are some uncertainties associated with the potential of generating power in a large-scale by the CCHS. Five major challenges are identified here.

First, are there enough existing conventional hydropower facilities with suitable and resourceful sites around world to extract additional energy economically? Sørnes (2010) states that generating small-scale hydropower from hydrokinetic turbines is particularly attractive to remote communities across the world for many remote communities are located near rivers [12]. In this paper, the discussion is more interested in the sites with potential of providing power in the magnitude of megawatts (MW) by deploying CCHS. Therefore, its targeted application area is within the vicinity of large-scale existing conventional hydropower stations in big rivers. Inherent with this challenge is the definition and assessment of a "resourceful site". Smaller installations to the existing hydropower stations or installations with the ability to reduce flow rates may be the attractive retrofit starting points. More attractive application still (through cost reductions from economies of scale) would be adding RISHTs to new construction hydropower facilities to establish CCHS as fully designed projects.

To address the challenge of resourceful site assessment, it is necessary to investigate the macro and micro scale site features in the vicinity of existing large-scale conventional hydropower facilities, analyse the characteristics of rives, and determine the energy density and the annual energy yield [16]. For determining the potential sites' energy density, it needs to acquire the temporal and spatial flow properties of a river along with its depth and cross section features. Establishing a global database of river characteristics within the vicinity of large-scale conventional hydropower facilities would be an important and helpful first step to access river energy and the potential of combined-cycle hydropower systems.

The second challenge is the assessment of environmental impacts posed by adding the RISHTs to the downstream of existing conventional hydropower facilities. The production of electricity by hydrokinetic turbines is sustainable and without emitting greenhouse gas; represents a kind of clean energy. However, the combine-cycle hydropower technology is in its starting phases, it is necessary to determine what types of environmental effects may be caused from its deployment. The hydrokinetic devices are assembled and rotated underwater. There could be concerns on the system's impacts on river animal, plant, hydrologic and sediment regimes [5, 16-18]. However, the water passing through hydrokinetic turbines already has debris filtered out by the conventional hydropower facility. As water passing through the hydrokinetic generator is the same water which has just passed through the conventional water turbine, the additional environmental impact should be minimal. This would imply that the hydrokinetic generator's output is relatively speaking operationally safer [19].

To address the challenge of environmental impact assessment, it requires conducting the comprehensive valuations or simulations on the downstream flow adversities on aquatic 
plant and animals, as well as navigation and transport factors [16, 20, 21]. An estimation of survival of fish passed through the Hydro Green Energy (HGE) hydrokinetic turbine system, and a characterization of fish entrainment potential at Mississippi Lock and Dam No. 2 Hydroelectric Project has been conducted. The evaluation has concluded that the HGE hydrokinetic unit has little if any considerable impact on the fish populations in the vicinity of the Mississippi Lock and Dam No. 2 Hydroelectric Project [22]. This investigation provides a good example of addressing the hydrokinetic turbines' impacts on aquatic animals. Through appropriate site selection, project design, and proper preventive measures, the environmental impacts posed by the CCHS can be minimized [23].

The third challenge is the technical availability. As an emerging and novel way of using RISHTs to establish CCHS, the development of this technology is still in its early stage. There are demonstrations of RISHTs, however, they are in general small in scale and less publicized [6]. Adding RISHTs to the existing conventional hydropower facilities to establish the CCHS to produce extra power outputs in large scale is inevitably more complicated which needs to consider both operation conditions of hydrokinetic turbines and water turbines of hydropower stations. The optimum design of a RISHT to fit into site specifications is also a significant challenge. It needs the optimum design, configuration, and integration of a variety of components such as, rotor, channel augmentation, mounting, flotation, mooring, power converter, control instruments and protection devices [6].

The fourth challenge which is also the most dominant one affects the potential and success of the CCHS is the cost of energy. There are some factors influencing relative economic costs of installing RISHTs at a particular site, including: 1) turbine's design current speed; 2) river velocity distribution; 3) number of installed turbine units; 4) turbine reliability and operation and maintenance (O\&M) procedures; 5) insurance cost; and 6) permitting, detailed design and environmental monitoring cost [11]. The design current speed is the maximum velocity of water expected to occur at the site. It can have a major influence on the cost of the structural elements. The velocity distribution is used to calculate the annual energy output of the turbine at the installation site. In general, a larger number of turbine units installed will result in lower cost of electricity. The turbine component reliability directly impacts the O\&M cost of a turbine. The insurance cost can vary greatly depending on the project risks. Hence, the cost of a CCHS may be comprised of the sub-costs as capital cost, operations and maintenance cost, design simplicity, diversity of applications, modularity, scalability, material and labour engagement, and availability of off-the-shelf components [5].

According to EPRI's 2008 economic feasibility study on Alaska river in-stream power plants, the capital cost of a 30-unit turbine array with total rated capacity of $593 \mathrm{~kW}$ was at US\$3071 [11]. This estimated capital costs of RISHTs system has not been yet commercial attractive which was more expensive than wind energy, but much cheaper than solar energy [24]. Nevertheless, in 2011, HGE estimates the cost per $\mathrm{kWh}$ for the RISHT's would be in the range of US $\$ 0.03-U S \$ 0.07$ based on its presently undergoing 28 RISHT projects. This is at the lower end of the cost of renewable energy technologies where onshore wind, off shore wind and solar estimates fall in the ranges of US\$0.05$\$ 0.08$, US\$0.08-\$0.12, and US\$0.12-\$0.25 respectively [25]. For the RISHT technology, if these estimates are accountable, these cost estimates represent a potential competitive market entrant. 
Finally, as will all installations, other factors like system reliability, societal acceptance, and system performance may also have impact on the system [16].

\section{Advantages}

The CCHS is able to harvest extra renewable energy which has advantages compared to building new conventional hydropower plants or generating power from distributed and intermittent renewable energy sources like wind or solar energy.

Man-made water-head like dams or penstocks is required for the operation of conventional hydropower plants. In contrast, adding the RISHTs into river stream does not change the natural pathway of flow in a significant way. Hence, it can provide extra clean energy with minimal requirement for construction work, less impact on environment, less noise and aesthetics issues.

Unlike wind energy, the outflow from the dam is predictable with very small flow variations. Therefore, the hydrokinetic turbine system would require less stringent fast acting control and protection methods. Because the strength and direction of wind change all the time, it requires equipping wind turbines with direction sensing and alignment devices. In contrast, the outflow of dam is unidirectional and the placement of hydrokinetic turbine with fixed orientations would be adequate for its most applications.

The convenience of electricity grid connection would be another advantage for the CCHS compared to distributed renewable energy sources. It would face minimum grid interconnectivity or transmission line access challenges. It would be able to utilize the existing grid connection infrastructure at the site of conventional hydropower stations. It would not require expensive infrastructure upgrades or new installations with long transmission lines requiring isolated maintenance work.

The conventional hydropower facility often operates with a high capacity factor. By adding RISHTs directly behind or in the downstream of conventional hydropower facility, the power generation from the hydrokinetic turbines can possess the same characteristics as the hydroelectric generators and be predictable. This is preferable to the intermittent renewable energy sources.

Attaching the hydrokinetic turbines to large scale conventional hydropower facilities generates additional power from the outflows of dam which increases the power generation capacity from the existing hydropower facilities. This approach of extracting additional large amount of renewable energy could be attractive to the developing countries with rapid growth of energy demand and large amount of existing conventional hydropower facilities, such as China, India, and Brazil. Moreover, it could provide an additional resource which could add to the attractiveness of new hydropower projects under construction.

\section{Examples of Combined-Cycle Hydropower System}

The conjunct use of conventional hydropower stations and RISHTs to increase the extraction of river kinetics can have two modes of hydrokinetic turbine placement. The hydrokinetic turbine can be located directly behind the turbine of the existing conventional hydropower plant or it can be placed at sites in the vicinity of powerhouse. CCHS represents both of these two modes. These two modes of hydrokinetic turbine placement have been demonstrated by the project of the Hastings hydrokinetic power station on the Mississippi river, Minnesota and the resource assessment and feasibility study for hydrokinetic turbines in the tailwaters of the Priest Rapids Project in Washington State in the USA. 
The Hastings hydrokinetic project uses a one-to-one turbine to locate hydrokinetic turbine directly behind the water turbine of the existing conventional hydropower plant to generate additional power from the energy remaining in the water current exiting the dam and flowing downstream. It is the first-of-its-kind barge-mounted power project in the USA to receive a federal license. The power project includes two turbines installed downstream of an existing 4.4MW run-of-river hydropower plant [26].

The deployment of turbines downstream from the existing hydropower facilities is patented and named as $\mathrm{Hydro}^{+}$by the developer HGE [27]. The equipment is expected to generate as much as $250 \mathrm{~kW}$, representing a $5.7 \%$ increase in renewable energy generation at the Hastings site. The hydrokinetic power station consists of modular, interchangeable and zero-head turbines, a $68 \mathrm{ft}$-wide and $20 \mathrm{ft}$-long floating barge through which the turbines are suspended, generating units atop the barge and a power transmission line that connects the existing powerhouse's transmission line. The floating barge is also anchored for stability [28].

Arango (2011) has conducted a study of analysing the stretch of the Columbia River downstream from the Wanapum and Priest Rapids Dams to access the feasibility of introducing hydrokinetic turbines in the tailwaters of dams for extracting kinetic power found in the tailwaters [13]. In Arango's research, four sites are considered as being feasible for using hydrokinetic turbines, and four different hydrokinetic turbines that are currently available or are scheduled to be variable in the near future, were selected according to sites' water depths and flow velocities as the viable technologies to introduce in the tailrace waters.

For each dam, the powerhouse vicinity is of interest to place hydrokinetic turbines because of the residual energy of discharging water flow at the outlet of the powerhouse draft tubes. For the downstream sites from the Wanapum Dam, the sites of about $80 \mathrm{~m}$ in front of unit 6 of the Wanapum powerhouse and at approximately 1400m downstream from the left embankment of the Wanapum Dam were chosen. For the downstream sites from the Priest Rapids Dam, the spots of about $35 \mathrm{~m}$ from the draft tube outlet of unit 4 of the Priest Rapids powerhouse and close to $550 \mathrm{~m}$ from the Priest Rapids powerhouse were selected.

The turbine rated at $50 \mathrm{~kW}$ manufactured by Tocardo International BV was considered for the downstream site $550 \mathrm{~m}$ away from the Priest Rapids powerhouse. The performance and placement of each turbine is examined according to information available from the manufacturers and based on the characteristics of the sites. The study results showed that each hydrokinetic turbine can extract the power from tailrace waters at certain proportions of their designed capacities at each site.

These two cases have demonstrated the possibility and feasibility of the conjunction use of RISHTs with the existing conventional hydropower plants. Although they are both the examples of the applications of RISHTs with low power capacity to produce extra power generation at small-scale, they do provide evidences of proof of concept. They are providing data to analyse the combined use of hydrokinetic turbines with the existing hydropower plants to produce additional power and information regarding the aspects of resources assessment, site identification, hydrokinetic turbine selection, and the advantages to this form of renewable power production.

\section{Potential Benefits}

As a potential clean way of generating electricity from renewable energy source, the CCHS would possess the potential benefits of contributing to climate change mitigation. 
This technology would have special implication for the rapid developing countries with rich hydropower resources like China which have high growth of energy demand and face the imminent pressure from international community on reducing their carbon emissions at the same time.

Estimating market penetration and the scale of potential production from a specific energy technology is always difficult [29]. The diffusion of a new energy technology often has distinguishing phases, starting with a slow market entry, followed by a growth phase and finally ending in market saturation [30]. It may be well impacted by the factors like availability and spreading of information among market actors and users, cost and risk factors, volume and size effects, political and public acceptance, and environmental impacts etc. [31].

Presuming that major challenges of developing CCHS mentioned above are well addressed, key factors affecting market growth of CCHS remain favourable in the future, and the energy systems dynamics resemble past patterns, for illustration purposes, let us assume that the market penetration by 2020 was on average $0.1 \%$ of total generation or alternatively, $5 \%$ of newly constructed hydroelectric generation.

The estimated total world hydroelectric generating capacity in 2012 was 960 Gigawatts $(\mathrm{GW})$. By 2020, it is estimated that the total world hydroelectric generation capacity will increase by $235 \mathrm{GW}$ to $1,195 \mathrm{GW}$ [32]. This change represents an increase of approximately $24 \%$.

At an average rate of $0.1 \%$ on total hydroelectric generation, the additional generation due to combined cycle hydroelectric generation would be $11.95 \mathrm{GW}$ by 2020 . If we assume a $5 \%$ market penetration on newly constructed generation instead, then the increase in generation is $11.75 \mathrm{GW}$. Obviously, these estimates are highly speculative. The estimates are for illustrative purposes only. For countries with adequate electrical generation supplies, the incentives to adopt a CCHS generation technology may not be attractive and so the estimates are too high. For energy starved countries such as China, trying to maximize the available electrical output, the estimates may be conservative. It is estimated that the majority of the hydroelectric growth $(85 \%)$ will occur in non-OECD countries [32].

Regardless, if we allow the production through the application of the CCHS approach to approximately increase hydroelectric generation by $11.75 \mathrm{GW}$, this represents the production of approximately twenty-nine $400 \mathrm{MW}$ coal-fired power plants. If these coal fired power plants were replaced by the CCHS, the annual avoided $\mathrm{CO}_{2}$ emissions would be of approximately 81 million metric tonnes.

\section{Discussion and Conclusion}

The CCHS would be able to produce clean power in large-scale sustainable manner, and contribute to global climate change mitigation, only if the major challenges mentioned above are addressed.

Generally speaking, RISHT technology is still at a very early stage of development. Except for some early commercial systems (small-scale power generation from remote river streams), most of the hydrokinetic energy conversion technologies are at the proofof-concept or system research and development stage [14].

Recent technological advancement and project-development initiatives clearly suggest an invigorated interest in the development of hydrokinetic energy conversion technology [14]. Carbon Trust published a report in 2006 stated that wave and tidal stream 
technology is at a similar stage to wind technology in the 1970s and early 1980s [33]. Technological advancement in tidal energy conversion which employs the same principle as RISHTs is relatively mature. Tidal energy conversion technology would be the valuable reference for developing the river in-stream turbine technology. Many of the devices may have the potential to be scaled to fit a broader range of river flow and depth characteristics [6].

Technically speaking, RISHTs can take advantages of rapid advances in many electrical, mechanical, computational, and material technologies, which include durable composite materials, low speed generators, underwater construction advancements, and fish monitoring technology, CAD-CAM, CFD modelling, anti-corrosion materials, and high efficiency power electronics [6]. Most of components like blades, generator, and power converter needed for designing a RISHT system are technologically available. Therefore, product development cycle, cost and level of technical sophistication are expected to be relatively low for this technology when it reaches mature [16].

The cost of one electricity generation technology plays an important role in determining its prosperity while competing with other types of energy technologies in the market. Hence, addressing the challenge of cost competitiveness is the most decisive one for the success of CCHS. If it could be proven through a larger scale project that adding the hydrokinetic turbine to the existing conventional hydropower facilities to generate large scale additional power can be achieved cost effectively, the CCHS system would be a very attractive new technology. Although the combined-cycle hydroelectric power system requires more components other than the hydrokinetic turbines, the cost data presented above provided by the HGE Company gives us a hope that the CCHS could be achievable in an economic way.

More technical and feasibility analysis is needed. To more comprehensively analyse the feasibility of the CCHS, it would be helpful to conduct a scaled up conceptual systemlevel design, performance, and economic study of the conjunction generation of RISHTs and conventional hydropower facilities. The baseline study used for the performance and economic study could be established on a selected large-scale conventional hydropower station. Based on the selected hydropower station, this kind of study would conduct the site selection, hydraulic impact assessment and environmental impact assessment for constructing the CCHS. According to the results of site investigation and selection, a baseline device design consisting of certain type of hydrokinetic turbine will be performed. Then, a parametric performance, cost and economic model can be established to adapt the technology to the other specific site conditions [11]. The cost estimates from the baseline study can be cross-checked with data provided by the hydrokinetic turbines manufactures which would provide a good reference for the economic feasibility of CCHS.

\section{References}

[1] RESOLVE Inc. Proceedings of the Hydrokinetic and Wave Energy Technologies Technical and Environmental Issues Workshop. In: Schwartz SS, editor. Washington, D. C.2005.

[2] Ortega-Achury SL, McAnally WH, Davis TE, Martin JL. Hydrokinetic power review. Prepared for the US Army Corps of Engineers Research and Development Center, Vicksburg, Mississippi. 2010.

[3] Kirke B. Developments in ducted water current turbines. Sustainable Energy Center, University of South Austrailia http://www cyberiad net/library/pdf/bk_tidal_paper25apr06 pdf (accessed August 16, 2011). 2003. 
[4] Güney M, Kaygusuz K. Hydrokinetic energy conversion systems: A technology status review. Renewable and Sustainable Energy Reviews. 2010;14:2996-3004.

[5] Khan M, Bhuyan G, Iqbal M, Quaicoe J. Hydrokinetic energy conversion systems and assessment of horizontal and vertical axis turbines for river and tidal applications: A technology status review. Applied Energy. 2009;86:1823-35.

[6] Verdant Power. Technology Evaluation of Existing and Emerging Technologies - Water Current Turbines for River Application. 2006.

[7] Radkey RL, Hibbs B. Definition of cost-effective river-turbine designs. NASA STI/Recon Technical Report N. 1981;83:20413.

[8] Fo GLT. The state of art of Hydrokinetic power in Brazil. 2003.

[9] Gorlov A. Harnessing power from ocean currents and tides. Sea Technology. 2004;45:40-3.

[10] Dixon DA, Bahleda M, Hosko MA. Assessment of waterpower potential and development needs: Electric Power Research Institute; 2007.

[11] Previsic M, Bedard R, Polagye B. System level design, performance, cost and economic assessment-Alaska river in-stream power plants. EPRI RP. 2008;6.

[12] Sørnes K. Small-scale Water Current Turbines for River Applications. 2010.

[13] Arango MA. Resource Assessment and Feasibility Study for Use of Hydrokinetic Turbines in the Tailwaters of the Priest Rapids Project: University of Washington; 2011.

[14] Khan MJ, Bhuyan G, Iqbal MT, Quaicoe JE. Hydrokinetic energy conversion systems and assessment of horizontal and vertical axis turbines for river and tidal applications: A technology status review. Applied Energy. 2009;86:1823-35.

[15] Hall DG. Feasibility Assessment of Water Energy Resources of the United States for New Low Power and Small Hydro Classes of Hydroelectric Plants. Department of Energy (DOE); 2006.

[16] Khan MJ, Iqbal MT, Quaicoe JE. River current energy conversion systems: Progress, prospects and challenges. Renewable and Sustainable Energy Reviews. 2008;12:2177-93.

[17] Grabbe M, Lalander E, Lundin S, Leijon M. A review of the tidal current energy resource in Norway. Renewable and Sustainable Energy Reviews. 2009;13:1898-909.

[18] Penche C. Layman's Handbook on How to Develop a Small Hydro Site, CEC DG TREN and ESHA, June 1998. 2004.

[19] Neville JDA. Hydrokinetic Plant Piggybacks on Existing Hydro Plant. Power. 2009;153:56-+. [20] Cada G, Ahlgrimm J, Bahleda M, Bigford T, Stavrakas SD, Hall D, et al. Potential impacts of hydrokinetic and wave energy conversion technologies on aquatic environments. Fisheries.

2007;32:174-81.

[21] Lalander E, Leijon M. In-stream energy converters in a river - Effects on upstream hydropower station. Renewable Energy. 2011;36:399-404.

[22] Normandeau Associates. An Estimation of Survival and Injury of Fish Passed Through the Hydro Green Energy Hydrokinetic System, and a Characterization of Fish Entrainment Potential At The Mississippi Lock and Dam No. 2 Hydroelectric Project (P-4306) Hastings, MinnesotaFinal Report. 2009.

[23] UCS. How Hydrokinetic Energy Works In: Scientists UoC, editor.: Union of Concerned Scientists; 2008.

[24] Diesendorf M. Economics of Nuclear and Renewable Electricity. Unpublished Briefing Paper, presented at the International Workshop on Nuclear Energy Singapore2010.

[25] Hydro Green Energy. Technology Comparison. 2011.

[26] Neville A. Hydrokinetic Plant Piggybacks on Existing Hydro Plant. Power: Tradefair Group; 2009.

[27] Hydro Green Energy. Who We Are. 2012.

[28] Power-Technology. Hastings Hydrokinetic Power Station, United States of America. Project Gallery: Net Resources International; 2012.

[29] Packey DJ. Market Penetrati Technologies. 1993.

[30] Rogers E. Diffusion of innovations: Free Pr; 1995.

[31] Lund P. Market penetration rates of new energy technologies. Energy Policy. 2006;34:331726. 
[32] EIA. Annual energy outlook. US Energy Information Administration. http://www. eia. gov/about/contact/forecasti ng. cfm\# longterm; 2011.

[33] Carbon Trust. Future marine energy: results of the marine energy challenge: cost competitiveness and growth of wave and tidal stream energy: Carbon Trust; 2006. 